\title{
Una lanza por Martina Vinatea
}

\section{Jorge Wiesse Rebagliati}

\section{Resumen}

El autor reseña la publicación Epistola de Amarilis a Belardo, edición, estudio preliminar y notas preparadas por Martina Vinatea Recoba. Se trata de un trabajo en el que destacan el nivel de solvencia intelectual, de talento investigativo y de dominio de fuentes de la investigadora peruana.

Palabras clave: Epístola de Amarilis a Belardo, literatura epistolar, Siglo de Oro español

\section{Abstract}

The autor notes the new Epistola de Amarilis a Belardo edition, with preliminary studies and notes prepared by Martina Vinatea Recoba. Vinatea's intellectual solvency level, investigative talent and mastery on the sources are the main virtues of this edition.

Key words: Epístola de Amarilis a Belardo, epistolary literature, Spanish Golden Age

To solo la ignorancia, también la amistad puede ser osada. No tengo más títulos que el 1 ser amigo de Martina Vinatea que justifiquen el referirme a su edición de la Epistola de Amarilis a Belardo, recientemente publicada por la editorial Iberoamericana-Vervuert dentro de la Biblioteca Indiana, prestigiosa colección cuidada por el Centro de Estudios Indianos de la Universidad de Navarra.

Sin embargo, desde otro ángulo, la amistad —y una amistad tan dilatada- - podría otorgarme alguna ventaja y podría justificar también algunas omisiones. Empiezo por las omisiones. En efecto, no cabe aquí una impertinente laudatio (aunque evidentes, no sería de buen gusto que yo — su amigo- pondere los amplios méritos humanos y académicos de Martina). No me corresponde, tampoco, comentar detalladamente las excelencias de su edición, pues no soy especialista en el tema. 
Sigo con la ventaja. En realidad, más que ventaja, se trata de un privilegio: el haber asistido como testigo al proceso de creación intelectual que precedió y que, hasta cierto punto, aún envuelve con su aura a esta obra. Como es un proceso que nos interpela, en tanto humanos y en tanto universitarios, me permitiré no solo reseńarlo, sino reflexionar brevemente a partir de él.

Puede ser que el germen de esta obra haya surgido del gusto de Martina por la poesía, y, más específicamente, por la indeclinable materialidad de la poesía, que es el sonido. Martina gusta de recitar, hace recitar a sus hijos y a sus alumnos y les enseña que lo oral y lo auditivo no están reñidos ni con el ingenio ni con la belleza. Su pasión por la poesía del Siglo de Oro español y sus correlatos indianos pudo haber tenido que ver con la elección del texto de la Epistola para trabajarlo a profundidad. No puedo dejar de pensar en que las clases de Carlos Gatti, Juana Truel y Enrique Carrión debieron reforzar en ella afinidades largamente sentidas. De esa época, 1984, es su estudio sobre el plano de la expresión (o sea el plano sonoro) de la Epistola que terminó en una elogiada memoria de Bachillerato. El patrón cuantitativo, acentual, tonal y tímbrico del texto, así como la determinación de la estrofa (no era una silva, como la había clasificado Menéndez y Pelayo en el siglo XIX, y varios luego de él, sino una canción, una canción petrarquista, como lo sugirió, pero solo lo sugirió, Aurelio Miró Quesada en el siglo XX) ya estaban claros para Martina desde ese tiempo. Martina, además, revisó y corrigió la puntuación para que el sentido del texto quedara absolutamente claro. Finalmente, resolvió con criterio los problemas de hiper-e hipometría que presentaban algunos versos (en este último caso, notó que se trataba de versos en los que aparecía la /h/ aspirada, lo que impedía la sinalefa, y por lo tanto, agregaba una sílaba al verso).

Más de 20 años después (con perdón de Dumas), Martina Vinatea retoma el texto de Amarilis. ¿Por qué? La respuesta más obvia, la lectio facilior, podría ser que estaba en medio de su doctorado y quería acudir a un texto conocido que no le daría mayores problemas. Sin embargo, la diferencia entre memoria y edición comentada es tal, el nivel de solvencia intelectual, de talento investigativo y de dominio de fuentes es tan patente en esta última, que me animo a otra explicación: durante más de 20 ańos Martina Vinatea se preparó para este trabajo; se preparó anímica, vital, volitivamente para este trabajo. No es un fenómeno extraño en las actividades del espíritu: como para negar los tiempos cortos y mezquinos que a veces se imponen a la creación, en ese testimonio excepcional titulado Cuaderno de notas a las "Memorias de Adriano", Marguerite Yourcenar relata cómo, en un lapso de 27 años (de 
1924 a 1951), entre idas y vueltas, estímulos y decepciones, días y noches febriles y largos tiempos muertos, concibió y ejecutó su novela. Como lo dice la misma Yourcenar, y — sin temor a la infidencia, esto puede aplicarse a Martina Vinatea-, hay libros que solo pueden escribirse luego de los 40 ańos.

Es un poco difícil explicar la fascinación que puede ejercer la investigación de un tema a alguien que está fuera de él o cuyos intereses no lo incluyen, pero algo hay en ella de novela policíaca, de crucigrama resuelto, de poema cumplido. Al final, se trata en todos estos casos, de resolver un enigma. Como el arqueólogo que descubre a punta de pinceles y cuadrículas el secreto diseño de una ciudad enterrada o como el restaurador de telas que reconstruye los hilos deshilvanados para encontrar una figura perdida, el investigador debe reconstruir, pero reconstruir es a veces sinónimo de crear. Y siempre, de ver, de contemplar. Probablemente el problema más frecuentado de la historia literaria del Perú sea el de la identidad de Amarilis. El texto daba algunas informaciones: mujer, de familia huanuqueña, monja, descendiente de conquistadores, hermana casada. Con esas informaciones, la crítica trató de identificar a la autora de la Epistola. Y fatigó archivos y genealogías. Martina Vinatea, en cambio, miró a otro lado, miró al texto. Y las hilachas se transformaron en tela. Las que propone son, ciertamente, solo "hipótesis verisímiles», como le gustaría decir a Cervantes, pero me seduce la idea de que uno de los problemas más intrincados de la historia literaria peruana pueda resolverse sencillamente oyendo al texto y haciéndolo hablar. Ya la estructura petrarquista de la Epistola es un índice al que no se había dado mucho valor, pero la verdadera protagonista de la argumentación de Martina es la estancia XV de esta, pues los topónimos citados en ella coinciden casi puntualmente con los que aparecen en el canto X de la traducción de Los Lusíadas de Camoens realizada por el minero perulero-portugués Enrique Garcés (quien también tradujo el Cancionero de Petrarca). ¿No habrá sido alguien del entorno de Garcés quien compuso la obra? Garcés no podía ser, pues la Epistola se refiere a obras de Lope de Vega aparecidas después de la muerte del minero. ¿No podría ser alguien vinculado familiarmente con Garcés, su hija Ana, por ejemplo, que fue monja y, según Lohmann y Monguió, escritora?

Bien por la hipótesis. Para llegar a ella, aunque no sea esta el único mérito de su edición ni mucho menos, Martina debió revisar y contrastar bibliografía, desempolvar legajos en archivos, viajar, a veces para certificar un solo dato puntual. Viene ahora la gran pregunta: ¿vale la pena todo esto?, ¿vale la pena sacrificar tiempos de familia, de amistad, de amor, para dedicarlos a una actividad que, desde fuera, parecería solo satisfacer un gusto 
exquisito, aunque probablemente inútil? ¿No es esta una forma más bien ociosa y hasta irresponsable de la existencia? Puede ser. Pero la pregunta merece una respuesta un poco más demorada. Me gustaría empezar a desarrollarla citando un texto de Constantino Carvallo sobre el ocio, la creación y sus productos recogidos en su libro Diario educar:

El ocio es la creación, la actividad libre que reconcilia libertad y naturaleza. Y su resultado no es el producto, sino la obra. Un trozo de mundo que es como debe ser, un extrańo ente de infinito lenguaje que apela al mismo tiempo al entendimiento y a la imaginación. Sin utilidad, como la de una herramienta o unas monedas. $\mathrm{Y}$ que, sin embargo, nos comunica con los otros, y nos ayuda a crear un mundo común cuyo sustento es el gusto semejante, la comunidad que la obra reclama. El ocio es la atmósfera que la libertad requiere para mirar las cosas como si fueran nuevas, con asombro y con amor. Un amor que engendra, que actúa. Y que, al hacerlo, hace nacer una obra -un cuadro, una danza, una canción- capaz de mostrarse y formar un mundo de espectadores unidos en la contemplación y en su deleite plural. (Constantino Carvallo Rey, Diario educar, pp. 156-157)

El ocio es el perfume de nuestra existencia y las actividades ociosas, como la investigación de Martina — una investigación cuya utilidad no puede medirse de la misma manera que la de las monedas o la de las herramientas_-, nos envuelven en una atmósfera, en un ámbito (para usar el término de López-Quintás) en el que lo humano resulta más humano. Ciertamente, no hay que confundir el discurso primario de la Epistola de Amarilis con el discurso secundario que Martina ha creado para interpretarla. Pero todo esfuerzo para comprender mejor, para gustar mejor, para apropiarse mejor de una obra gratuita, es también una forma de gratuidad y al final, no es inútil, pues se incorpora a una comunidad, precisamente la comunidad de gozadores de la obra en cuestión, que se sentirán solicitados por la humanidad de esta y deberán responder con su humanidad a ella. Como afirma George Steiner:

En mi opinión, salta a la vista que el estudio, el argumento teológico-filosófico, la música clásica, la poesía, el arte, todo aquello que es «difícil porque es excelente» (Spinoza, santo patrón de los poseídos) son la excusa de la vida. Estoy convencido de que el mero hecho de ser miembros, comentaristas, instructores o guardianes secundarios de algunos de estos elevados lugares nos convierte en seres privilegiados. (George Steiner, Errata, p. 151). 
Martina Vinatea se ha acercado a uno de esos lugares elevados y ha vuelto posible que muchos también lo hagan. Nos ha convertido en privilegiados. En este sentido, también es maestra de gratuidad, de generosidad, de amor, de ocio transformado en obra.

Anónimo. Epistola de Amarilis a Belardo. Edición, estudio preliminar y notas de Martina Vinatea Recoba. Madrid-Frankfurt: Editorial Iberoamericana Vervuert, 2009, 172 pp. 